\title{
Current knowledge and future directions of TLR and NOD signaling in sepsis
}

Niamh M Foley ${ }^{1}$, Jian Wang ${ }^{2}$, H Paul Redmond ${ }^{1}$ and Jiang Huai Wang ${ }^{1 *}$

\begin{abstract}
The incidence of sepsis is increasing over time, along with an increased risk of dying from the condition. Sepsis care costs billions annually in the United States. Death from sepsis is understood to be a complex process, driven by a lack of normal immune homeostatic functions and excessive production of proinflammatory cytokines, which leads to multi-organ failure. The Toll-like receptor (TLR) family, one of whose members was initially discovered in Drosophila, performs an important role in the recognition of microbial pathogens. These pattern recognition receptors (PRRs), upon sensing invading microorganisms, activate intracellular signal transduction pathways. NOD signaling is also involved in the recognition of bacteria and acts synergistically with the TLR family in initiating an efficient immune response for the eradication of invading microbial pathogens. TLRs and NOD1/NOD2 respond to different pathogen-associated molecular patterns (PAMPs). Modulation of both TLR and NOD signaling is an area of research that has prompted much excitement and debate as a therapeutic strategy in the management of sepsis. Molecules targeting TLR and NOD signaling pathways exist but regrettably thus far none have proven efficacy from clinical trials.
\end{abstract}

Keywords: Innate immunity, TLR signaling, NOD signaling, Sepsis

\section{Introduction}

Sepsis remains a significant global burden, notwithstanding the noteworthy breakthroughs that have been made in our understanding of the molecular mechanisms involved. Sepsis has been identified as one of five conditions accounting for the most costly hospital length of stays in the United States [1]. The body's response to sepsis is both intricate and diverse. Since the initial finding of the Toll-like receptor (TLR) in Drosophila, mapping of the pathways involved in the immune response to sepsis has grown significantly. TLRs and NOD-like receptors (NLRs) are the two main members of the family of pattern recognition receptors (PRRs) and are involved in the recognition of invading microbial pathogens. Both TLR and NOD signaling act synergistically in the initiation of the host innate immune response to bacterial infection. This involves the activation of intracellular signal transduction pathways and culminates in the production and release of proinflammatory cytokines. The

\footnotetext{
* Correspondence: jh.wang@ucc.ie

'Department of Academic Surgery, University College Cork, Cork University Hospital, Cork, Ireland

Full list of author information is available at the end of the article
}

targeting of these molecules and pathways presents potential therapeutic strategies in the treatment of sepsis. Unfortunately, to date, there have been no commercially available successful strategies in targeting the molecular pathways involved in sepsis. Disparities in the patient population and comorbid conditions complicate the development of successful strategies targeting various steps in the signaling pathways. In this review article we aim to highlight research to date on TLR and NOD signaling in sepsis and therapeutic strategies targeting these pathways.

\section{Incidence and mortality of sepsis}

Sepsis is defined as the presence (probable or documented) of infection together with systemic manifestations of infection [2]. Several different terms have been used to describe the overwhelming inflammatory response associated with acute infections including septicemia, sepsis and septic shock. Considering the wide range of terms and the absence of tangible definitions, a consensus meeting was convened in 1992. The American College of Chest Physicians/ Society for Critical Care Medicine (ACCP/SCCM) [3] sepsis definitions from this conference described sepsis as the 
clinical or microbiological evidence of infection along with two out of four of the following parameters:

- Temperature $>38^{\circ} \mathrm{C}$ or $<36^{\circ} \mathrm{C}$;

- Heart rate $>90$ bpm;

- Hyperventilation $>20 \mathrm{resps} / \mathrm{min}$ or $\mathrm{Pa}_{\mathrm{CO} 2}<32$ mmHg;

- White cell counts $>12,000$ cells $/ \mu \mathrm{l}$ or $<4,000 \mathrm{cell} / \mu \mathrm{l}$.

These criteria were subsequently updated in the Society of Critical Care Medicine/European Society of Intensive Care Medicine/American College of Chest Physicians/ American Thoracic Society/Surgical Infection Society (SCCM/ESICM/ACCP/ATS/SIS) International Sepsis Definitions Conference in 2001 (Table 1) [4]. The range of criteria included reflects the difficulty that has existed in the definition of sepsis. Sepsis is a systemic, deleterious host response to infection leading to severe sepsis and septic shock [5].

In the United States severe sepsis is the tenth leading overall cause of death, similar to the numbers dying from acute myocardial infarction. The risk of dying from sepsis is rising year on year [6,7]. Mortality associated with severe sepsis is estimated at $30 \%-50 \%[8,9]$. Treatment in the initial hours after the onset of sepsis influences outcome. Significant variability exists in reported severe sepsis mortality with a rate of $8.6 \%$ (range $0.9 \%$ 18.2\%) across 188 hospitals in the United States [10], though a further study reported higher in-hospital mortality rates ranging from $14.7 \%-29.9 \%$ [11]. Sepsis is a global financial burden [1]. The costs associated with sepsis care are mainly related to the price of targeted new therapies such as activated protein $C$, which costs $\$ 27,936$ per life year gained [12], technologies and also the increasing charges for fixed costs. Angus and coworkers estimated the cost of sepsis treatment in the United States in 2001 at $\$ 16.7$ billion annually [13]. This figure had risen to $\$ 24.3$ billion by 2007 [8].

The vast majority of severe sepsis cases are as a result of infection with either gram-positive or gram-negative bacteria. The incidence of gram-positive sepsis has increased over time and is now almost as common as gramnegative sepsis [14]. In a 2006 European multicentre study, a respiratory source $(68 \%)$ of sepsis was the commonest site involved, followed by an intra-abdominal source (22\%) [15]. The same study revealed the most common isolate as Staphylococcus aureus, followed by Pseudomonas species and Escherichia coli. The Extended Study on the Prevalence of Infection in Intensive Care (EPIC II) also found a predominant respiratory source of sepsis (64\%), with $62 \%$ of isolated bacteria being gram-negative microorganisms [16]. The most commonly isolated gramnegative bacteria were Pseudomonas species, Escherichia coli and Klebsiella species. Staphylococcus aureus was one
Table 1 Diagnostic criteria for sepsis reproduced from the Society of Critical Care Medicine/European Society of Intensive Care Medicine/American College of Chest Physicians/American Thoracic Society/Surgical Infection Society (SCCM/ESICM/ACCP/ATS/SIS) International Sepsis Definitions Conference in 2001

\begin{tabular}{ll}
\hline Infection $^{(\mathbf{1})}:$ Documented or suspected and some of the following \\
\hline General & Fever (core temperature $>38.3^{\circ} \mathrm{C}$ ) \\
parameters & Hypothermia (core temperature $<36^{\circ} \mathrm{C}$ ) \\
& Heart rate $>90$ beats per minute or $>2 \mathrm{SD}$ above \\
& the normal value for age \\
& Tachypnoea $>30$ breaths per minute \\
& Altered mental state \\
& Significant oedema or positive fluid balance \\
& $(>20 \mathrm{ml} / \mathrm{kg}$ over 24 hrs) \\
& Hyperglycaemia (plasma glucose $>110 \mathrm{mg} / \mathrm{dL}$ or \\
& $7.7 \mathrm{mmol} / \mathrm{L}$ in the absence of diabetes
\end{tabular}

Inflammatory Leukocytosis (white blood cell count $>12,000 / \mu \mathrm{L}$ ) parameters Leukopaenia (white blood cell count $<4,000 / \mu \mathrm{L}$ )

Normal white blood cell count with $>10 \%$ immature forms

Plasma $C$ reactive protein $>2$ SD above the normal value

Plasma procalcitonin >2 SD above the normal value

Haemodynamic Arterial hypotension ${ }^{(2)}$ (systolic blood pressure parameters $\quad<90 \mathrm{mmHg}$, mean arterial pressure $<70 \mathrm{mmHg}$ or a systolic blood pressure decrease $>40 \mathrm{mmHg}$ in adults or $<2$ SD below the normal value for age)

Mixed venous oxygen saturation $>70 \%^{(2)}$

Cardiac index $>3.5 \mathrm{~L} / \mathrm{min} / \mathrm{m}^{2(3,4)}$

Organ dysfunction Arterial hypoxaemia $\left(\mathrm{PaO}_{2} / \mathrm{FiO}_{2}<300\right)$ parameters

Acute oliguria (urine output $<0.5 \mathrm{ml} / \mathrm{kg} / \mathrm{hr}$ or $45 \mathrm{mmol} / \mathrm{L}$ for at least $2 \mathrm{hrs}$ )

Creatinine increase $\geq 0.5 \mathrm{mg} / \mathrm{dL}$

Coagulation abnormalities (international normalised ratio $>1.5$ or activated partial thromboplastin time $>60$ seconds)

lleus (absent bowel sounds)

Thrombocytopenia (platelet count <100,000/ $\mu \mathrm{L}$ )

Hyperbilirubinaemia (plasma total bilirubin $>4 \mathrm{mg} / \mathrm{dL}$ or $70 \mathrm{mmol} / \mathrm{L}$ )

Tissue perfusion Hyperlactatemia ( $>3 \mathrm{mmol} / \mathrm{L}$ )

parameters

Decreased capillary refill or mottling

\footnotetext{
(1)Defined as a pathological process induced by microorganisms.

${ }^{(2)}$ Values above $70 \%$ are normal in children and should therefore not be used as a sign of sepsis in newborns or children.

${ }^{(3)}$ Values of 3.5-5.5 are normal in children and should therefore not be used as a sign of sepsis in newborns or children.

${ }^{(4)}$ Diagnostic criteria for sepsis in the paediatric population is signs and symptoms of inflammation plus infection with hyper- or hypothermia rectal temperature $>38.5^{\circ} \mathrm{C}$ or $\left\langle 35^{\circ} \mathrm{C}\right.$, tachycardia (may be absent in hypothermic patients) and at least one of the following indications of altered organ function, altered mental status, hypoxemia, elevated serum lactate levels, and bounding pulses.
} 
of the most commonly isolated gram-positive bacteria followed by Staphylococcus epidermidis and Streptococcus pneumonia. The same study, using multivariate analysis, found that gram-negative bacteria, namely Pseudomonas, Enterococcus and Acinetobacter species, were associated with a greater risk of in-hospital mortality. The increasing incidence of gram-positive bacterial infection is possibly a result of the increasing numbers of invasive procedures and the increasing risk of developing hospital acquired infections [17].

Sir William Osler noted that death from sepsis results from the response of the body to systemic infection as opposed to the infection itself. This view was expanded on in the 1970's and is now a widely accepted concept [18]. Death in the first few days from sepsis is generally understood to be a result of hyper-inflammation driven by inflammatory cytokines, which leads to multi-organ failure. Herein lies a complex dysregulation of the immune system with loss of immune homeostasis.

\section{Host innate immunity and related innate immune responses to microbial infection}

The immune system affords the host an opportunity to respond to pathogenic microorganisms and incorporates innate and adaptive immunity. Innate immunity is a generic response to the recognition of invading microbial pathogens and defined as being "dependent on germline genes, present at all times and functional during early primary infections but not increasing with repeated exposure [19]". By contrast, adaptive immunity is dependent on the "rearrangement of genes, antigen specific and requiring time for induction during primary challenges [19]". Therefore, the innate immune system forms the first line of defense against microbial infection, and is activated by the engagement of germline-encoded innate immune receptors, also known as pattern recognition receptors (PRRs) in response to invading microbial pathogens $[5,20,21]$. PRRs expressed on innate immune cells such as polymorphonuclear neutrophils (PMNs) and monocytes/macrophages recognize the presence of highly conserved and unique structures of microbial pathogens called pathogen-associated molecular patterns (PAMPs) as well as detect endogenous damageassociated molecular patterns (DAMPs) generated in the setting of cellular damage or tissue injury $[20,22,23]$. This generic response enables the detection of a finite number of molecules that are common and conserved in different pathogenic microbes, for example lipopolysaccharide (LPS) or lipid A that is common to all gramnegative bacteria and lipoteichoic acid (LTA) that is common to all gram-positive bacteria. Recognition of these PAMPs by PRRs during microbial infection results in activation of signal transduction pathways and initiates both inflammatory and antimicrobial responses, which ultimately culminate in eliminating the invading microbial pathogens $[5,20,21,24]$.

Monocytes/macrophages, PMNs and dendritic cells (DCs) are all salient elements of the host innate immune response. Natural killer cells, once thought to be solely a component of the innate immune system are now recognized to possess features associated with adaptive immunity also. These cells can directly or indirectly target pathogenic microorganisms through phagocytosis or by releasing substances such as inflammatory cytokines, chemokines and other mediators. Macrophages, derived from peripheral blood mononuclear cells, are predominantly resident in tissues and are particularly abundant in liver, lung and gut tissue, where the body is exposed to most foreign pathogens. Phagocytosis of invading microbial pathogens by macrophages initiates the innate immune response. The inflammatory response to invading pathogens is characterized by the release of a variety of different inflammatory mediators, including proinflammatory cytokines and chemokines, adhesion molecules, reactive oxygen species (ROS) and enzymes. This vital step in the elimination of microbial pathogens from the host can result in an overwhelming inflammatory response. Overproduction of proinflammatory cytokines can lead to an amplified and dysregulated secondary response. This hyper-inflammatory state, with the loss of normal immune homeostasis, ultimately causes tissue damage and organ dysfunction. A delicate balance exists between mounting a sufficient immune response to clear invading microbes and a negative feedback system to prevent inflammationinduced pathology. As a form of protection a period of immune hypo-responsiveness, also known as endotoxin tolerance, can occur with repeated LPS stimulation and is associated with the reduced survival seen in patients with septic shock [25].

Bacteria that cause diseases in humans can be divided into two broad categories, extracellular pathogens and intracellular pathogens [26,27]. Intracellular pathogens invade host cells and have the ability to survive and replicate within the cell [26]. In contrast, extracellular pathogens have developed ways to survive outside of host cells, as phagocytic uptake of these bacteria results in their rapid elimination [27]. These diverse strategies, used by bacteria to cause diseases, denote that the host has to develop a broad arsenal of defense mechanisms to protect themselves, for example the existence of both extracellular and intracellular PRRs as well as PRRtriggered immune responses $[5,20,21,28,29]$. To date, at least five major classes of PRRs have been identified, which include two families of membrane-bound PRRs: Toll-like receptors (TLRs) and C-type lectin receptors (CLR), and three families of cytoplasmic PRRs: the nucleotide binding and oligomerization domain (NOD)-like receptors (NLRs), retinoic acid-inducible gene (RIG)-I- 
like receptors (RLRs) and absence in melanoma 2 (Aim 2)-like receptors [28-30]. Among these PRRs, the TLRs and NLRs are two major classes of PRRs that are primarily responsible for the recognition of molecular structures of bacterial origin [30-33].

\section{TLR signaling and related intracellular signal transduction pathways in response to microbial infection}

The transmembrane TLRs, with an extracellular domain involved in bacterial ligand recognition, are the most widely described PRRs. TLR1, TLR2, TLR4, TLR5, TLR6, and TLR10 are located at the extracellular surface, whereas TLR3, TLR7, TLR8, and TLR9 are located in the endoplasmic reticulum and endosomes $[21,30,32,34]$. TLRs were initially investigated in Drosophila [35], which has no adaptive immune system [36]. Eleven TLRs have been discovered in humans and thirteen in mice [37] and they, or their homologues, are found in all multicellular organisms [38]. Species differences do occur in the TLRs, which complicates attempts at cross-species direct comparisons. TLR2 and TLR4, which are expressed on the cell surface, are perhaps the most widely investigated of the TLR family and the only TLRs shown to be responsive to microbial ligands [39]. LPS or endotoxin, derived from gram-negative bacteria almost exclusively activates its primary receptor TLR4, one of the most studied pathways in host innate immunity against gram-negative bacterial infection. TLR4, initially named hToll was discovered in the 1990's, when Hoshino and colleagues, using TLR4-deficient mice, demonstrated the hypo-responsiveness of these animals to LPS stimulation [40], thus confirming the pivotal role of TLR4 in the response to LPS. TLR4-deficient mice have been shown to be susceptible to gram-negative bacterial infection. In addition, specially bred mice that exclusively expressed TLR4 on endothelial cells were found to be more efficient at clearing Escherichia coli infection [41]. Smirnva et al., on examining DNA from patients with meningococcal disease found that a variant in the TLR4 gene is associated with an increased susceptibility to meningococcal septicemia [42]. Genetic variants in the TLR4 have also been linked to gram-negative bacterial infection in neonates [43]. TLR2, on the other hand, forms heterodimers TLR2/TLR1 and TLR2/TLR6 with either TLR1 or TLR6, and is a functional receptor for components of gram-positive bacteria including LTA, peptidoglycan (PGN) and bacterial lipopeptides, thus being responsible for the detection of gram-positive bacteria [44-46]. TLR2-deficient mice are highly susceptible to gram-negative Staphylococcus aureus infection, with significantly attenuated TNF- $\alpha$ and IL- 6 production [47]. TLR5 and TLR9 recognize flagellin of bacteria flagella and bacterial CpG-DNA [21,48], respectively.

Upon engagement with their specific ligands, TLRs activate several intracellular signaling pathways. Signaling by TLRs in humans involves a family of five adaptor proteins, which interact with downstream protein kinases that ultimately lead to the activation of transcription factors including nuclear factor- $\mathrm{kB}(\mathrm{NF}-\mathrm{kB})$ and members of the interferon (IFN)-regulatory factor (IRF) family. The Toll/interleukin-1 (IL-1) receptor (TIR) domain, which is unique to the TLR system, is the key signaling domain for not only TLRs, but also the adaptor protein. These five adaptor proteins include myeloid differentiation factor 88 (MyD88), MyD88 adaptor-like (MAL) protein, TIR-domain-containing adaptor protein inducing IFN- $\beta$ (TRIF), TRIF-related adaptor molecule (TRAM) and sterile- $\alpha$ and armadillo-motif-containing protein (SARM) [49]. MAL, TRIF and TRAM are also known as TIR domain-containing adaptor protein (TIRAP), TIR-containing adaptor molecule-1 (TICAM1) and TICAM2. All TLRs (except TLR3) activate the MyD88 pathway, which results in the activation predominantly of the downstream NF- $\mathrm{KB}$ and mitogen-activated protein kinase (MAPK) signaling pathways, and ultimately leads to the production of inflammatory cytokines. Upon stimulation, MyD88 recruits IL-1 receptorassociated kinase (IRAK) family to TLRs and IRAK1 then associates with TNF receptor-associated factor 6 (TRAF6). This subsequently leads to the activation of NF$\kappa \mathrm{B}$ as well as MAPKs including $\mathrm{p} 38$, c-Jun NH2-terminal kinase (JNK) and extracellular signal-related kinase 1/2 (ERK1/2) [50]. Macrophages and DCs isolated from MyD88-deficient mice have been shown to be unable to respond to certain TLR ligands including TLR2, TLR5, TLR7 and TLR9 [51], indicating that these TLRs are fully dependent on the MyD88 signaling in order to activate the NF- $\mathrm{kB}$ signaling pathway. These cells however can remain somewhat responsive to LPS stimulation through a MyD88-independent pathway. TLR3 and TLR4 can activate a MyD88-independent/TRIF-dependent pathway, which allows for the activation of NF- $\mathrm{kB}$ and IRF3, and induction of IFN- $\beta$. TRIF (also known as TICAM1) activates TRAF3 and TRAF6, and signaling from TRAF3 induces IRF3 activation which allows for the production of IFN- $\beta$. Mice lacking TRIF fail to generate a type I IFN response to LPS stimulation, though their ability to activate the NF$\kappa B$ and MAPK signaling pathways is preserved [52]. TRAM links TRIF to TLR4 and studies have shown TLR4 to possess the most complex signaling mechanism of all the TLRs, as TLR4 is the only member of the TLR family that recruits four adaptor proteins MyD88, MAL, TRIF and TRAM and activates two signaling pathways, namely the MyD88- and TRIF-dependent pathways [53].

\section{NOD signaling and related intracellular signal} transduction pathways in response to microbial infection NLRs are the newly discovered PRRs and are located in the intracellular cytoplasm [31,33,54-56]. Currently, 
23 NLR proteins have been described in humans, and there are at least 34 TLR genes in mice [57]. NLR proteins are expressed by most human immune cells as well as a variety of non-immune cells including astrocytes, microglial cells, osteoblasts, myofibroblasts and epithelial cells [58]. This family of proteins is characterized by a tripartite structure consisting of i) a variable downstream protein-protein interaction domain, defined as the caspase activation and recruitment domain (CARD), a pyrin domain (PYD) or the baculovirus inhibitor repeat (BIR) domain; ii) a centrally located NOD domain or the central NACHT nucleotide-binding domain that facilitates oligomerization during activation and; iii) a C-terminal leucine-rich repeat (LRR) domain that detects PAMPs $[33,54,55]$. The LRR domain is pivotal in NLR activation following stimulation with bacterial products [59]. Oligomerisation of the central NACHT nucleotide-binding domain is another crucial step in NLR activation, with this step enabling the NF- $\mathrm{kB}$ mediated inflammatory response [60].

In contrast to the TLR family, the function of the majority of NLRs is poorly defined. However, NOD1 and NOD2, which play an important role in the intracellular recognition of invading pathogenic bacteria, are the two most comprehensively investigated members of the NLR family and have been shown to sense different structural core motifs derived from PGN, a cell wall component present in both gram-positive and gram-negative bacteria [61-64]. NOD1 is ubiquitously expressed in both stromal and hematopoietic cells [65], whereas NOD2 is only expressed in leukocytes including monocytes/macrophages and DCs, and in epithelial cells upon inflammatory stimulation [66]. NOD1 recognizes a PGN-related molecule containing the amino acid meso-diaminopimelic acid (meso-DAP) that is produced by most gram-negative and certain gram-positive bacteria [61,62], whereas NOD2 senses muramyl dipeptide (MDP) that is a conserved PGN motif present in all gram-positive and gram-negative bacteria $[63,64]$. Similar to TLR signaling, once activated, NOD1 and NOD2 enable their CARD domain to recruit and activate the adaptor protein, serine threonine kinase RICK, also known as receptor interacting protein 2 (RIP2). Activation of RIP2 is essential for the recruitment of TAK1, a kinase required for the activation of both the MAPK and IKK complex [67]. Subsequently, RIP2-induced activation of the IKK complex results in the phosphorylation and degradation of the inhibitor of $\kappa B \alpha(\mathrm{I} \kappa \mathrm{B} \alpha)$, a critical step that allows for the nuclear translocation of NF- $\mathrm{kB}$. The IKK complex also activates the MAPK family. Activation of the downstream NF- $\mathrm{KB}$ and MAPK signal transduction pathways stimulates the transcription and production of inflammatory cytokines and chemokines, which drive the host innate immune response to different infectious microbes. NOD1 not only activates NF- $\mathrm{kB}$, but also MAPK
JNK as seen in infection with Shigella flexneri [68]. Streptococcus pneumonia, another intracellular pathogen upregulates the expression of NOD1 and NOD2, with NOD2 playing an important role in the activation of downstream signaling molecules, which coordinate the activation of NF-kB [69].

Bacteria can activate NOD signaling by two different mechanisms; the T3SS, which has been identified in a number of gram-negative bacteria, is related to the flagellum and its main function is to deliver effector molecules across the cellular membrane of the host, whereas the T4SS, which has been identified in both gram-positive and gram-negative bacteria, is related to the bacterial conjugation system and can deliver DNA and proteins to the host cell [70]. Helicobacter pylori strains with functional T4SS, which delivers PGN intracellularly, were identified as potent activators of NOD1 [71]. NOD1-deficient mice are susceptible to infection with Staphylococcus aureus [72] and Helicobacter pylori [71]. Macrophages derived from NOD1-deficient mice are hyporesponsive to mesoDAP [61]. NOD2-deficient mice show enhanced susceptibility to Toxoplasma gondii infection [73]. Aberrant NOD2 signaling is strongly implicated in Crohn's disease [74], whereby a defect in the LRR domain leads to an abnormal response to stimulation by bacterial components [63]. It is postulated that the normal hypo-responsiveness that exists to gut microflora becomes deranged in Crohn's disease, causing an excessive inflammatory response to antigens within the microflora [75]. RIP2-deficient mice display an inability to respond to bacterial infection, underlining the importance of this molecule in NOD signaling [76]. RIP2deficient mice also display impaired MAPK activation and attenuated cytokine responses. Stimulation of either NOD1 or NOD2 fails to activate the NF- $\mathrm{kB}$ pathway in fibroblasts derived from mice deficient in RIP2 and furthermore, RIP2-deficient mice display enhanced susceptibility to Listeria monocytogenes infection [77].

\section{Interaction and coordination between TLR and NOD signaling in innate immunity against microbial infection} The presence of PRRs located in multiple compartments of host cells raises questions about the reason for the development of microbial sensors with different cellular localizations. It is generally acknowledged that the location of the PRRs can dictate the type of bacteria they sense, for example, the cell surface PRRs such as the TLRs are activated primarily by extracellular bacteria, whereas the cytoplasmic PRRs like the NLRs, in particular NOD1 and NOD2, are responsible for sensing intracellular bacteria that are capable of breaching the plasma membrane and entering the cytoplasm [28,29]. However, emerging evidence has suggested that this is an inaccurate classification for extracellular and intracellular PRRs [69,72,78-80]. Indeed, many extracellular 
bacteria such as Staphylococcus aureus and Streptococcus pneumonia can be sensed by the cytoplasmic PRRs, NOD1 and NOD2 [69,72,78]. Conversely, TLR9, which senses CpG-containing DNA fragments, is responsible for the recognition of both extracellular and intracellular bacteria $[79,80]$. Furthermore, it has been reported that the maturation of bacteria-containing phagosomes is induced and accelerated in a TLR-dependent manner [81], suggesting that TLR signaling controls the maturation of phagosomes and destruction of captured microbial pathogens, including not only the extracellular bacteria but also the intracellular bacteria. It is more likely, therefore, that the role of extracellular and intracellular PPRs is to work together in order to induce an efficient innate immune response for the eradication of invading microbial pathogens, including both extracellular and intracellular bacteria from the body.

TLRs and NOD1/NOD2 collaborate with one another in mounting and balancing an efficient innate immune response to microbial pathogens. Both TLRs and NOD1/ NOD2 respond to different PAMPs, which in some cases can be delivered by the same bacteria. Most TLRs activate the downstream NF- $\mathrm{kB}$ and MAPK pathways through recruitment and activation of their adaptor protein MyD88, whereas NOD1 and NOD2 activate the downstream NF$\kappa B$ pathway through recruitment and activation of their adaptor proteins RIP2 and CARD9. Much investigation has been undertaken over the last number of years to elucidate the crosstalk that exists at different levels between the TLRs and NLRs. The TLR and NRL pathways can work synergistically in the host innate immune response to bacterial infection. Co-stimulation of human monocytes and DCs with the NOD1 agonist MtriDAP, the NOD2 agonists MDP and MtriLYS, and the TLR4 agonist LPS leads to enhanced production of inflammatory cytokines [82]. RIP2 is essential for activation of both NOD1- and NOD2-mediated signaling pathways; however, RIP2-knockout mice have defects in TLR2, TLR3 and TLR4 signaling [83]. RIP2-deficient mice have been shown to be more susceptible to pulmonary infection with Chlamydophila pneumonia [84] and are also more susceptible to infection with Listeria monocytogenes [85]. While NOD2 is essential for the recognition of MDP [86], MDP can increase the sensitivity of cells to LPS stimulation up to three-fold [87]. TLRs and NOD1/ NOD2 also work synergistically in the production and maturation of IL-1 $\beta$ [88]. NOD2 is involved in the cleavage of pro-IL-1 $\beta$ to its active form by caspase-1, while TLRs, through the NF- $k B$ pathway, allow for induction of pro-IL-1 $\beta$ [78].

Several mechanisms involved in the crosstalk between TLRs and NOD1/NOD2 have been proposed, which include upregulation of MyD88 expression in MDPstimulated cells [89] and modulation of TLR signaling by the interaction of NOD2 and TAK1, a downstream molecule in the TLR signaling pathway [90]. The ability of MDP to augment the reaction of human monocytes and DCs to LPS stimulation is well documented [82]. LPS treatment stimulates NOD2 expression and TLR stimulation enhances the NOD2 response [91], through either upregulation of NOD2 or by induction of pro-IL$1 \beta$ [92]. The essential roles of both TLR and NOD signaling pathways in the activation of IL- $1 \beta$ may act as a safeguard against excessive cytokine production. There appears to be a lack of cross-tolerisation between the TLR and NOD signaling pathways, with macrophages that are tolerant to the TLR4 agonist LPS remaining responsive to the NOD1 agonist mesoDAP and the NOD2 agonist MDP [93]. This may serve as an important backup mechanism for the host innate immune system in conditions where the tolerisation to TLR-associated signaling occurs. Cells also develop tolerance to NOD2 signaling with repeated exposure to the NOD2 agonist MDP [94]. This process is thought to be mediated by the rapid degradation of NOD2 protein, though these cells remain competent to stimulation with TLR ligands [94]. A separate experiment confirmed the ability of NOD2deficient mice to react to TLR ligands despite having an impaired ability to mount a Th2-type response following stimulation with MDP [95]. This lack of cross-tolerisation may serve to preserve the host ability to mount an immune response to bacteria via NOD signaling, even in the TLR-tolerised state. It is important to note that some published papers did describe cross-tolerisation following stimulation of immune cells with NOD1/NOD2 agonists followed by TLR agonists; however, this effect may be due to impurities within the agonists used, the timing of pretreatment, or the type of cells used in the experiment.

\section{Novel therapeutic strategies for treatment of sepsis by targeting both TLR and NOD signaling}

Over the past twenty years significant breakthroughs have been encountered in our understanding of the molecular mechanism(s) responsible for PRRs, PAMPS and the related signal transduction pathways involved in host innate immune responses to microbial infection. Targeted therapies can be directed at different phases of the host reaction to the invading microbial pathogens; however, there has been a dearth of potential therapies progressing to clinical trials and those that have, unfortunately so far proven ineffective. The immune system itself is a balance between proinflammatory and anti-inflammatory signals with multiple positive and negative feedback loops and complex signaling mechanisms. Both the hyper- and hypo-immune response must be taken into account with any potential therapies. Targeting individual molecules, however, is rife with problems. 


\section{Modulating TLR signaling}

Interrupting different molecular mechanisms at play in TLR signaling has been made possible by the development of antagonistic molecules.

Targeting TLR4 High mobility group box protein-1 (HMGB1), released by innate immune cells, signals through TLR4. Reduced HMGB1 levels in caspase-1deficient mice correlate with the resistance of these mice to LPS-associated lethality [96]. Anti-HMGB1 antibodies ameliorated the severity of sepsis in a cecal ligation and puncture (CLP)-induced polymicrobial sepsis model in rat [97]. Eritoran, an antagonist of the LPSMD2-TLR4 complex, which blocked LPS-induced inflammatory cytokine response in vitro and in vivo, failed to produce any discernable benefit in reducing the mortality of patients with severe sepsis in a randomized, doubleblind, and placebo-controlled phase 3 clinical trial [98]. Anti-TLR4 antibodies have been investigated in animal models of sepsis, with a reported benefit in certain studies $[99,100]$, though a recent paper suggested no survival benefit in an Escherichia coli-induced abdominal sepsis model in mice [101]. TLR4 signaling is dependent on MyD88, which has been examined as an exciting potential therapeutic target for the treatment of sepsis. Research has shown that blocking the MyD88 adaptor protein substantially attenuates the IL- $1 \beta$-driven inflammatory cytokine response to staphylococcal enterotoxin [102]. BAY 11-7082, an anti-inflammatory drug, which targets the MyD88 signaling pathway and potently inhibits NLRP3 activity [103], has not yet advanced to clinical trials. TAK242 is a small molecule specific and selective inhibitor of TLR4. It binds to the TIR domain of TLR4 and also inhibits the binding of TIRAP and TRAM to TLR4, thus attenuating the production of LPS-induced inflammatory mediators [104]. In a murine model of Escherichia coliinduced peritonitis, a significant survival advantage was seen in mice treated with both TAK-242 and ceftazidime an hour following bacterial challenge [105]. Additionally, administration of TAK-242 strongly attenuated serum levels of proinflammatory cytokines in a murine endotoxic shock model and protected mice against LPSinduced lethality when mice were treated one hour before and 4 hours after LPS challenge [106]. Although TAK-242 showed great promise in experimental models of sepsis [107], it was withdrawn due to a lack of efficacy in a phase 3 clinical trial $[108,109]$. Despite the disappointing results seen in clinical trials with TLR4 antagonists, much research and excitement still persists in this field.

TLR2 antagonists T2.5, an anti-TLR2 monoclonal antibody, inhibited inflammatory mediators and prevented lethal shock in a murine model of sepsis using Bacillus subtilis [110]. When T2.5 was used in combination with a TLR4-MD2 antagonist up to 4 hours after infection with Escherichia coli or Salmonella enterica, the survival benefit in mice was even greater [111].

TLR3 antagonists In addition to the recognition of viral double-stranded RNA, TLR3 also senses DAMPs, which tend to be produced as a result of cellular damage or tissue injury in response to inflammation. A study in murine models of both cecal ligation-induced gut ischemia and CLP-induced septic peritonitis revealed that an anti-TLR3 neutralizing antibody ameliorated tissue injury associated with gut ischemia and also significantly improved survival in mice challenged with CLP-induced polymicrobial sepsis [112].

\section{Modulating NOD signaling}

In contrast to the TLR signaling, NOD signaling is less well-characterized as a therapeutic target during microbial infection and sepsis. Several studies have examined the role of NOD agonists in abrogating the severity of sepsis associated with bacterial infection. In a murine model of Escherichia coli bacteraemia and sepsis, there was disease abrogation in animals treated with MDP and tuftsin, two compounds acting in an immunomodulatory fashion by stimulating bacterial phagocytosis and inflammatory cytokine release, thereby enhancing host defense [113]. The NOD2 agonist MDP is too pyrogenic to be used in the clinical setting and therefore several MDP derivatives without this side-effect have been investigated. The MDP derivative, murabutide, has been examined for its role in enhancing the host innate immune response to microbial infection, although a trial did not find significantly higher levels of circulating inflammatory cytokines in healthy volunteers [114]. Nevertheless, NOD agonists, when used prophylactically as adjuncts to antibiotics, substantially improve survival in animal models of microbial sepsis [115]. A patent currently exists on the use of a TLR9 agonist/ TLR4 antagonist and/or NOD2 agonist for the treatment of systemic sepsis and necrotizing enterocolitis [116]. Activation of TLR9 inhibits TLR4 signaling in enterocytes, leading to abrogation of the inflammatory reaction, whereas activation of NOD2 also led to a reduction in TLR4 signaling in treated enterocytes. TLR9 agonists promote a type I IFN response [117], thus enhancing bacterial phagocytosis and killing in experiments using Salmonella typhimurium [118] and Streptococcus pneumonia [119].

\section{Conclusion}

Sepsis is a leading cause of death in intensive care units worldwide. Factors associated with increased risk of sepsis include male race, extremes of age, comorbid medical conditions and people of African-American descent. Our knowledge of the molecular mechanisms involved in sepsis continues to grow. The innate immune system is 
vital in initiating the host defense against microbial pathogens; however, a dysregulated inflammatory response triggered by the innate immunity can be deleterious to the host. To date, clinical trials targeting TLRs and the related signaling pathways have failed. Several reasons are postulated for the lack of success including but not limited to the following: the extraordinary heterogeneity that exists in the septic population, comorbid conditions affecting individual patients, underpowered studies and the range of diagnostic criteria used in sepsis (Table 1). Also of importance is the fact that most animal models of human sepsis are deeply flawed. The systemic inflammatory response in mice is very different to that seen in humans, and is compressed into a few days whereas the human course can often follow a more protracted course, possibly related to the significant supportive care adjuncts that are in use in intensive care units [120]. These factors contribute to difficulties in translating promising preclinical targets in animal experiments into practical applications in human sepsis. In this review we have attempted to describe the roles of TLR and NOD signaling in host defense against microbial infection and the potential therapeutic strategies targeting both TLR and NOD signaling. Our understanding of the interplay between TLR and NOD signaling is rapidly expanding, contributing to the potential for future targeted therapies aimed at ameliorating the global morbidity and mortality related to microbial sepsis. At present, no clinical trials are actively examining TLR or NOD targeted therapies. These authors remain hopeful that successful targeted therapies will be developed in the future.

\footnotetext{
Abbreviations

ACCP: American College of Chest Physicians; Aim 2: Absence in melanoma 2; ATS: American Thoracic Society; BIR: Baculovirus inhibitor repeat; CARD: Caspase activation and recruitment domain; CLP: Cecum ligation and puncture; CLR: C-type lectin receptors; DAMPs: Damage-associated molecular patterns; DCs: Dendritic cells; EPIC: Extended Study on the Prevalence of Infection in Intensive Care; ERK1/2: Extracellular signal-related kinase 1/2; ESICM: European Society of Intensive Care Medicine; IFN: Interferon; IKBa: Inhibitor of KBa; IL-1: Interleukin-1; IRAK: IL-1 receptor-associated kinase; IRF: IFN-regulatory factor; JNK: c-Jun $\mathrm{NH}_{2}$-terminal kinase;

LPS: Lipopolysaccharide; LRR: Leucine-rich repeat; LTA: Lipoteichoic acid; MAL: MyD88 adaptor-like; MAPK: Mitogen-activated protein kinase; MDP: Muramyl dipeptide; MyD88: Myeloid differentiation factor 88; NF-kB: Nuclear factor-kB; NLRs: NOD-like receptors; PAMPs: Pathogenassociated molecular patterns; PMNs: Polymorphonuclear neutrophils; PRRs: Pattern recognition receptors; PYD: Pyrin domain; RIG: Retinoic acid-inducible gene; RIP2: Receptor interacting protein 2; RLRs: RIG-I-like receptors; ROS: Reactive oxygen species; SARM: Sterile-a and armadillomotif-containing; SCCM: Society for Critical Care Medicine; SIS: Surgical Infection Society; TICAM1: TIR-containing adaptor molecule-1; TIR: Toll/IL-1 receptor; TIRAP: TIR domain-containing adaptor protein; TLR: Toll-like receptor; TRAF6: TNF receptor-associated factor 6; TRAM: TRIF-related adaptor
} molecule; TRIF: TIR-domain-containing adaptor protein inducing IFN- $\beta$.

\section{Competing interests}

The authors declare that they have no competing interests.

\section{Authors' contributions}

All authors contributed equally to this manuscript. NMF, JW and JHW contributed to manuscript preparation. HPR and JHW edited and approved the final draft. All authors read and approved the final version of manuscript.

\section{Acknowledgements}

This work was supported by the National Natural Science Foundation of China (Grant 81420108022), Jiangsu Province Program of Innovative and Entrepreneurial Talents (2011-2014).

\section{Author details}

${ }^{1}$ Department of Academic Surgery, University College Cork, Cork University Hospital, Cork, Ireland. 'Department of Pediatric Surgery, Affiliated Children's Hospital, Soochow University, Suzhou 215003, China.

Received: 12 November 2014 Accepted: 17 December 2014

Published online: 07 January 2015

\section{References}

1. Chalupka AN, Talmor D. The economics of sepsis. Crit Care Clin. 2012;28:57-76.

2. Dellinger RP, Levy MM, Rhodes A, Annane D, Gerlach H, Opal SM, et al. Surviving sepsis campaign: international guidelines for management of severe sepsis and septic shock: 2012. Intensive Care Med. 2013;39:165-228.

3. American College of Chest Physicians/Society of Critical Care Medicine Consensus Conference. Definitions for sepsis and organ failure and guidelines for the use of innovative therapies in sepsis. Crit Care Med. 1992;20:864-874.

4. Levy MM, Fink MP, Marshall JC, Abraham E, Angus D, Cook D, et al. SCCM/ ESICM/ACCP/ATS/SIS international sepsis definitions conference. Crit Care Med. 2003;31:1250-1256.

5. Medzhitov R. Recognition of microorganisms and activation of the immune response. Nature. 2007;449:819-826.

6. Martin GS. Sepsis, severe sepsis and septic shock: changes in incidence, pathogens and outcomes. Expert Rev Anti Infect Ther. 2012;10:701-706.

7. Hall MJ, Williams SN, DeFrances CJ, Golosinskiy A. Inpatient care for septicemia or sepsis: a challenge for patients and hospitals. NCHS Data Brief. 2011;62:1-8.

8. Lagu T, Rothberg MB, Shieh MS, Pekow PS, Steingrub JS, Lindenauer PK. Hospitalizations, costs, and outcomes of severe sepsis in the United States 2003 to 2007. Crit Care Med. 2012;40:754-761.

9. Stevenson EK, Rubenstein AR, Radin GT, Wiener RS, Walkey AJ. Two decades of mortality trends among patients with severe sepsis: a comparative meta-analysis. Crit Care Med. 2014;42:625-631.

10. Wang HE, Donnelly JP, Shapiro NI Hohmann SF, Levitan EB: Hospital variations in severe sepsis mortality. Am J Med Qual 2014, May 9. [Epub ahead of print].

11. Gaieski DF, Edwards JM, Kallan MJ, Carr BG. Benchmarking the incidence and mortality of severe sepsis in the United States. Crit Care Med. 2013;41:1167-1174.

12. Manns BJ, Lee H, Doig CJ, Johnson D, Donaldson C. An economic evaluation of activated protein C treatment for severe sepsis. N Engl J Med. 2002;347:993-1000.

13. Angus DC, Linde-Zwirbler WT, Lidicker J, Clermont G, Carcillo J, Pinksy MR. Epidemiology of severe sepsis in the United States: analysis of incidence, outcome and associated costs of care. Crit Care Med. 2001;29:1303-1310.

14. Martin GS, Mannino DM, Eaton S, Moss M. The epidemiology of sepsis in the United States from 1979 through 2000. N Engl J Med. 2003;348:1546-1554.

15. Vincent $J L$, Sakr Y, Sprung CL, Ranieri VM, Reinhart K, Gerlach H, et al. Sepsis Occurrence in Acutely III Patients Investigators: Sepsis in European intensive care units: Results of the SOAP study. Crit Care Med. 2006;34:344-353.

16. Vincent JL, Rello J, Marshall J, Silva E, Anzueto A, Martin CD, et al. EPIC ॥ Group of Investigators: International study of the prevalence and outcomes of infection in intensive care units. JAMA. 2009;302:2323-2329.

17. Friedman G, Silva E, Vincent JL. Has the mortality of septic shock changed with time. Crit Care Med. 1998;26:2078-2086

18. Thomas L. Germs. N Engl J Med. 1972;287:553-555.

19. Biron CA. More things in heaven and earth: defining innate and adaptive immunity. Nat Immunol. 2010;11:1080-1082

20. Ishii KJ, Koyama S, Nakagawa A, Coban C, Akira S. Host innate immune receptors and beyond: making sense of microbial infections. Cell Host Microbe. 2008;3:352-363.

21. Akira S, Uematsu S, Takeuchi O. Pathogen recognition and innate immunity, Cell. 2006;124:783-801.

22. Bianchi ME. DAMPs, PAMPs and alarmins: all we need to know about danger. J Leukoc Biol. 2007;81:1-5. 
23. Matzinger $P$. The danger model: a renewed sense of self. Science. 2002:296:301-305.

24. Brodsky IE, Medzhitov R. Targeting of immune signalling networks by bacterial pathogens. Nat Cell Biol. 2009;11:521-526.

25. West MA, Heagy W. Endotoxin tolerance: a review. Crit Care Med. 2002;30: S64-S73.

26. Raupach B, Kaufmann SH. Immune responses to intracellular bacteria. Curr Opin Immunol. 2001;13:417-428.

27. Weiser JN, Nahm MH. Immunity to extracellular bacteria. In: Paul WE, editor. Fundamental Immunology. 6th ed. Philadelphia: Wolters Kluwer Health/ Lippincott Williams \& Wilkins; 2008. p. 1182-1203.

28. Meylan E, Tschopp J, Karin M. Intracellular pattern recognition receptors in the host response. Nature. 2006;442:39-44.

29. Núñez G. Intracellular sensors of microbes and danger. Immunol Rev. 2011;243:5-8.

30. Kopp E, Medzhitov R. Recognition of microbial infection by Toll-like receptors. Curr Opin Immunol. 2003;15:396-401.

31. Kanneganti TD, Lamkanfi M, Núñez G. Intracellular NOD-like receptors in host defense and disease. Immunity. 2007;27:549-559.

32. Modlin RL, Brightbill HD, Godowski PJ. The toll of innate immunity on microbial pathogens. N Engl J Med. 1999;340:1834-1835.

33. Chen G, Shaw MH, Kim YG, Nunez G. NOD-like receptors: role in innate immunity and inflammatory disease. Annu Rev Pathol. 2009:4:365-398.

34. Barton GM, Kagan JC. A cell biological view of Toll-like receptor function: regulation through compartmentalization. Nat Rev Immunol. 2009;9:535-542.

35. Belvin MP, Anderson KV. A conserved signaling pathway: the Drosophila toll-dorsal pathway. Annu Rev Cell Dev Biol. 1996;12:393-416.

36. Janeway CA, Medzhitov R. Lipoproteins take their toll on the host. Curr Biol. 1999:9:R879-R882.

37. Beutler BA. TLRs and innate immunity. Blood. 2009;113:1399-1407.

38. Janeway Jr CA, Medzhitov R. Innate immune recognition. Annu Rev Immunol. 2002;20:197-216.

39. Brightbill HD, Modlin RL. Toll-like receptors: molecular mechanisms of the mammalian immune response. Immunology. 2000;101:1-10

40. Hoshino K, Takeuchi O, Kawai T, Sanjo H, Ogawa T, Takeda Y, et al. Cutting edge: Toll-like receptor 4 (TLR4)-deficient mice are hyporesponsive to lipopolysaccharide: evidence for TLR4 as the Lps gene product. J Immunol. 1999;162:3749-3752

41. Andonegui G, Zhou H, Bullard D, Kelly MM, Mullaly SC, McDonald B, et al. Mice that exclusively express TLR4 on endothelial cells can efficiently clear a lethal systemic Gram-negative bacterial infection. J Clin Invest. 2009:119:1921-1930.

42. Smirnova I, Mann N, Dols A, Derkx HH, Hibberd ML, Levin M, et al. Assay of locus-specific genetic load implicates rare Toll-like receptor 4 mutations in meningococcal susceptibility. Proc Natl Acad Sci U S A. 2003;100:6075-6080.

43. Sampath V, Mulrooney NP, Garland JS, He J, Patel AL, Cohen JD, et al. Toll-like receptor genetic variants are associated with gram-negative infections in VLBW infants. J Perinatol. 2013;33:772-777.

44. Aliprantis AO, Yang RB, Mark MR, Suggett S, Devaux B, Radolf JD, et al. Cell activation and apoptosis by bacterial lipoproteins through toll-like receptor-2. Science. 1999:285:736-739.

45. Schwandner R, Dziarski R, Wesche H, Rothe M, Kirschning CJ. Peptidoglycanand lipoteichoic acid-induced cell activation is mediated by toll-like receptor 2. J Biol Chem. 1999;274:17406-17409.

46. Aderem A, Ulevitch RJ. Toll-like receptors in the induction of the innate immune response. Nature. 2000:406:782-787.

47. Takeuchi O, Hoshino K, Akira S. Cutting edge: TLR2-deficient and MyD88deficient mice are highly susceptible to Staphylococcus aureus infection. J Immunol. 2000;165:5392-5396.

48. Tian J, Avalos AM, Mao SY, Chen B, Senthil K, Wu H, et al. Toll-like receptor 9-dependent activation by DNA-containing immune complexes is mediated by HMGB1 and RAGE. Nat Immunol. 2007:8:487-496.

49. O'Neill LAJ, Golenbock D, Bowie AG. The history of Toll-like receptors: redefining innate immunity. Nat Rev Immunol. 2013;13:453-460.

50. Takeda K, Akira S. TLR signaling pathways. Semin Immunol. 2004;16:3-9.

51. Kawai T, Akira S. TLR signalling. Cell Death Differ. 2006;13:816-825.

52. Yamamoto M, Sato S, Hemmi H, Hoshino K, Kaisho T, Sanjo H, et al. Role of adaptor TRIF in the MyD88-independent toll-like receptor signaling pathway. Science. 2003;301:640-643.

53. Kawai T, Akira S. The role of pattern-recognition receptors in innate immunity: update on toll-like receptors. Nat Immunol. 2010;11:373-384.
54. Shaw MH, Reimer T, Kim YG. NOD-like receptors (NLRs): bona fide intracellular microbial sensors. Curr Opin Immunol. 2008;20:377-382.

55. Inohara N, Chamaillard M, MCDonald C, Nunez G. NOD-LRR proteins: role in host-microbial interactions and inflammatory disease. Annu Rev Biochem. 2005; $74: 355-383$.

56. Ting JP, Davis BK. CATERPILLER: a novel gene family important in immunity, cell death, and diseases. Annu Rev Immunol. 2005;23:387-414.

57. Fukata M, Vamadevan AS, Abreu MT. Toll-like receptors (TLRs) and Nod-like receptors (NLRs) in inflammatory disorders. Semin Immunol. 2009;21:242-253.

58. Fritz JH, Ferrero RL, Philpott DJ, Girardin SE. Nod-like proteins in immunity, inflammation and disease. Nat Immunol. 2006;7:1250-1257.

59. Ting JP, Lovering RC, Alnemri ES, Bertin J, Boss JM, Davis BK, et al. The NLR gene family: a standard nomenclature. Immunity. 2008;28:285-287.

60. Proell M, Riedl SJ, Fritz JH, Rojas AM, Schwarzenbacher R. The Nod-like receptor (NLR) family: a tale of similarities and differences. PLoS One. 2008;3:e2119.

61. Chamaillard M, Hashimoto M, Horie Y, Masumoto J, Qiu S, Saab L, et al. An essential role for NOD1 in host recognition of bacterial peptidoglycan containing diaminopimelic acid. Nat Immunol. 2003;4:702-707.

62. Girardin SE, Boneca IG, Carneiro LA, Antignac A, Jéhanno M, Viala J, et al. Nod1 detects a unique muropeptide from gram-negative bacterial peptidoglycan. Science. 2003;300:1584-1587.

63. Inohara N, Ogura Y, Fontalba A, Gutierrez O, Pons F, Crespo J, et al. Host recognition of bacterial muramyl dipeptide mediated through NOD2. Implications for Crohn's disease. J Biol Chem. 2003;278:5509-5512.

64. Girardin SE, Travassos LH, Hervé M, Blanot D, Boneca IG, Philpott DJ, et al. Nod2 is a general sensor of peptidoglycan through muramyl dipeptide (MDP) detection. J Biol Chem. 2003;278:8869-8872.

65. Inohara N, Koseki T, del Peso L, Hu Y, Yee C, Chen S, et al. Nod1, an Apaf-1-like activator of caspase-9 and nuclear factor-kappaB. J Biol Chem. 1999;274:14560-14567.

66. Gutierrez O, Pipaon C, Inohara N, Fontalba A, Ogura Y, Prosper F, et al. Induction of Nod2 in myelomonocytic and intestinal epithelial cells via nuclear factor-kappa B activation. J Biol Chem. 2002;277:41701-41705.

67. Hasegawa M, Fujimoto Y, Lucas PC, Nakano H, Fukase K, Nuñez G, et al. A critical role of RICK/RIP2 polyubiquitination in Nod-induced NF-kappaB activation. EMBO J. 2008;27:373-383.

68. Girardin SE, Tournebize R, Mavris M, Page AL, Li X, Stark GR, et al. CARD4/ Nod1 mediates NF-KB and JNK activation by invasive Shigella flexneri. EMBO Rep. 2001;2:736-742.

69. Opitz B, Püschel A, Schmeck B, Hocke AC, Rosseau S, Hammerschmidt S, et al. Nucleotide-binding oligomerization domain proteins are innate immune receptors for internalized Streptococcus pneumoniae. J Biol Chem. 2004:279:36426-36432.

70. Ferrand J, Ferrero RL. Recognition of extracellular bacteria by NLRs and its role in the development of adaptive immunity. Front Immunol. 2013;4:344.

71. Viala J, Chaput C, Boneca IG, Cardona A, Girardin SE, Moran AP, et al. Nod1 responds to peptidoglycan delivered by the Helicobacter pylori cag pathogenicity island. Nat Immunol. 2004;5:1166-1174.

72. Hruz P, Zinkernagel AS, Jenikova G, Botwin GJ, Hugot JP, Karin M, et al, NOD2 contributes to cutaneous defense against Staphylococcus aureus through alpha-toxin-dependent innate immune activation. Proc Natl Acad Sci U S A. 2009;106:12873-12878.

73. Shaw MH, Reimer T, Sanchez-Valdepenas C, Warner N, Kim YG, Fresno M, et al. T cell-intrinsic role of Nod2 in promoting type 1 immunity to Toxoplasma gondii. Nat Immunol. 2009;10:1267-1274.

74. Ogura Y, Bonen DK, Inohara N, Nicolae DL, Chen FF, Ramos R, et al. A frameshift mutation in NOD2 associated with increased susceptibility to Crohn's disease. Nature. 2001:411:603-606.

75. Strober W, Murray PJ, Kitani A, Watanabe T. Signalling pathways and molecular interactions of NOD1 and NOD2. Nat Rev Immunol. 2006;6:9-20.

76. Magalhaes JG, Lee J, Geddes K, Rubino S, Philpott DJ, Girardin SE. Essentia role of Rip2 in the modulation of innate and adaptive immunity triggered by Nod1 and Nod2 ligands. Eur J Immunol. 2011;41:1445-1455.

77. Chin Al, Dempsey PW, Brun K, Miller JF, Xu Y, Cheng G. Involvement of receptor-interacting protein 2 in innate and adaptive immune responses. Nature. 2002:416:190-194.

78. Deshmukh HS, Hamburger JB, Ahn SH, McCafferty DG, Yang SR, Fowler Jr VG. Critical role of NOD2 in regulating the immune response to Staphylococcus aureus. Infect Immun. 2009;77:1376-1382.

79. Bafica A, Santiago HC, Goldszmid R, Ropert C, Gazzinelli RT, Sher A. Cutting edge: TLR9 and TLR2 signaling together account for MyD88-dependent 
control of parasitemia in Trypanosoma cruzi infection. J Immunol. 2006;177:3515-3519.

80. Albiger B, Dahlberg S, Sandgren A, Wartha F, Beiter K, Katsuragi H, et al. Toll-like receptor 9 acts at an early stage in host defence against pneumococcal infection. Cell Microbiol. 2007;9:633-644.

81. Blander JM, Medzhitov R. Regulation of phagosome maturation by signals from toll-like receptors. Science. 2004;304:1014-1018.

82. Fritz JH, Girardin SE, Fitting C, Werts $C$, Mengin-Lecreulx D, Caroff M, et al. Synergistic stimulation of human monocytes and dendritic cells by Toll-like receptor 4 and NOD1- and NOD2-activating agonists. Eur J Immunol. 2005;35:2459-2470.

83. Meylan E, Tschopp J. The RIP kinases: crucial integrators of cellular stress. Trends Biochem Sci. 2005;30:151-159.

84. Shimada K, Chen S, Dempsey PW, Sorrentino R, Alsabeh R, Slepenkin AV, et al. The NOD/RIP2 pathway is essential for host defenses against Chlamydophila pneumoniae lung infection. PLoS Pathog. 2009;5:e1000379.

85. Philpott DJ, Girardin SE. The role of Toll-like receptors and Nod proteins in bacterial infection. Mol Immunol. 2004;41:1099-1108.

86. Kobayashi KS, Chamaillard M, Ogura Y, Henegariu O, Inohara N, Nunez G, et al. Nod2-dependent regulation of innate and adaptive immunity in the intestinal tract. Science. 2005;307:731-734.

87. Traub S, Kubasch N, Morath S, Kresse M, Hartung T, Schmidt RR, et al. Structural requirements of synthetic muropeptides to synergize with lipopolysaccharide in cytokine induction. J Biol Chem. 2004;279:8694-8700

88. Schwarz H, Posselt G, Wurm P, Ulbing M, Duschl A, Horejs-Hoeck J. TLR8 and NOD signaling synergistically induce the production of IL-1 $\beta$ and IL-23 in monocyte-derived DCs and enhance the expression of the feedback inhibitor SOCS2. Immunobiology. 2013;218:533-542.

89. Takada H, Yokoyama S, Yang S. Enhancement of endotoxin activity by muramyldipeptide. J Endotoxin Res. 2002;8:337-342.

90. Chen CM, Gong Y, Zhang M, Chen JJ. Reciprocal cross-talk between Nod2 and TAK1 signaling pathways. J Biol Chem. 2004;279:25876-25882

91. Tsai WH, Huang DY, Yu YH, Chen CY, Lin WW. Dual roles of NOD2 in TLR4mediated signal transduction and-induced inflammatory gene expression in macrophages. Cell Microbiol. 2011;13:717-730.

92. Davis BK, Wen H, Ting JPY. The inflammasome NLRs in immunity, inflammation, and associated diseases. Annu Rev Immunol. 2011;29:707-735.

93. Kim YG, Park JH, Shaw MH, Franchi L, Inohara N, Núñez G. The cytosolic sensors Nod 1 and Nod2 are critical for bacterial recognition and host defense after exposure to Toll-like receptor ligands. Immunity. 2008;28:246-257.

94. Lee KH, Biswas A, Liu YJ, Kobayashi KS. Proteasomal degradation of Nod2 protein mediates tolerance to bacterial cell wall components. J Biol Chem. 2012;287:39800-39811.

95. Magalhaes JG, Fritz JH, Le Bourhis L, Sellge G, Travassos LH, Selvanantham T, et al. Nod2-dependent Th2 polarization of antigen-specific immunity. J Immunol. 2008;181:7925-7935.

96. Lamkanfi M, Sarkar A, Vande Walle L, Vitari AC, Amer AO, Wewers MD, et al. Inflammasome-dependent release of the alarmin HMGB1 in endotoxemia. J Immunol. 2010;185:4385-4392.

97. Suda K, Kitagawa Y, Ozawa S, Saikawa Y, Ueda M, Ebina M, et al. Anti-high mobility group box chromosomal protein 1 antibodies improve survival of rats with sepsis. World J Surg. 2006;30:1755-1762.

98. Opal SM, Laterre PF, Francois B, LaRosa SP, Angus DC, Mira JP, et al. Effect of eritoran, an antagonist of MD2-TLR4, on mortality in patients with severe sepsis: the ACCESS randomized trial. JAMA. 2013;309:1154-6210.

99. Roger T, Froidevaux C, Le Roy D, Reymond MK, Chanson AL, Mauri D, et al. Protection from lethal gram-negative bacterial sepsis by targeting Toll-like receptor 4. Proc Natl Acad Sci U S A. 2009;106:2348-2352.

100. Daubeuf B, Mathison J, Spiller S, Hugues S, Herren S, Ferlin W, et al. TLR4/ MD2 monoclonal antibody therapy affords protection in experimental models of septic shock. J Immunol. 2007;179:6107-6114.

101. van Lieshout MH, van der Poll T, Van't Veer C. TLR4 inhibition impairs bacterial clearance in a therapeutic setting in murine abdominal sepsis. Inflamm Res. 2014;63:927-933.

102. Kissner TL, Moisan L, Mann E, Alam S, Ruthel G, Ulrich RG, et al. A small molecule that mimics the BB-loop in the Toll/L-1 receptor domain of MyD88 attenuates staphylococcal enterotoxin B-induced pro-inflammatory cytokine production and toxicity in mice. J Biol Chem. 2011;286:31385-31390

103. Juliana C, Fernandes-Alnemri T, Wu J, Datta P, Solorzano L, Yu JW, et al. Anti-inflammatory compounds parthenolide and Bay 11-7082 are direct inhibitors of the inflammasome. J Biol Chem. 2010;285:9792-9802.
104. Matsunaga N, Tsuchimori N, Matsumoto T, Ii M. TAK-242 (resatorvid), a small-molecule inhibitor of Toll-like receptor (TLR) 4 signaling, binds selectively to TLR4 and interferes with interactions between TLR4 and its adaptor molecules. Mol Pharmacol. 2011;79:34-41.

105. Takashima K, Matsunaga N, Yoshimatsu M, Hazeki K, Kaisho T, Uekata M, et al. Analysis of binding site for the novel small- molecule TLR4 signal transduction inhibitor TAK-242 and its therapeutic effect on mouse sepsis model. Br J Pharmacol. 2009;157:1250-1262.

106. Sha T, Sunamoto M, Kitazaki T, Sato J, li M, lizawa Y. Therapeutic effects of TAK-242, a novel selective Toll-like receptor 4 signal transduction inhibitor, in mouse endotoxin shock model. Eur J Pharmacol. 2007;571:231-239.

107. Sha T, lizawa Y, Ii M. Combination of Imipenem and Tak-242, a Toll-like receptor 4 signal transduction inhibitor, improves survival in a murine model of polymicrobial sepsis. Shock. 2011;35:205-209.

108. Takeda [http://www.takeda.com/news/2009/20090220_3678.html]

109. Rice T, Wheeler A, Bernard G, Vincent JL, Angus D, Aikawa N, et al. A randomized, double-blind, placebo-controlled trial of TAK-242 for the treatment of severe sepsis. Crit Care Med. 2010;38:1685-1694.

110. Meng G, Rutz M, Schiemann M, Metzger J, Grabiec A, Schwandner R, et al. Antagonistic antibody prevents Toll-like receptor 2-driven lethal shock-like syndromes. J Clin Invest. 2004;113:1473-1481.

111. Spiller S, Elson G, Ferstl R, Dreher S, Mueller T, Freudenberg M, et al. TLR4-induced IFN-gamma production increases TLR2 sensitivity and drives gram-negative sepsis in mice. J Exp Med. 2008;205:1747-1754.

112. Cavassani KA, Ishii M, Wen H, Schaller MA, Lincoln PM, Lukacs NW, et al. TLR3 is an endogenous sensor of tissue necrosis during acute inflammatory events. J Exp Med. 2008;205:2609-2621.

113. Wardowska A, Dzierzbicka K, Szarynska M, Dabrowska-Szponar M, Wisniewska K, Mysliwski A, et al. Analogues of muramyl dipeptide (MDP) and tuftsin limit infection and inflammation in murine model of sepsis. Vaccine. 2009;27:369-374.

114. Darcissac ECA, Vidal V, Guillaume M, Thebault JJ, Bahr GM. Clinical tolerance and profile of cytokine induction in healthy volunteers following the simultaneous administration of IFN- $a$ and the synthetic immunomodulator murabutide. J Interferon Cytokine Res. 2001;21:655-661.

115. Mine Y, Yokota Y, Wakai Y, Fukada S, Nishida M, Goto S, et al. Immunoactive peptides, FK-156 and FK-565. I. Enhancement of host resistance to microbial infection in mice. J Antibiot. 1983;36:1045-1050.

116. Hackam DJ, Gribar SC: Use of toll-like receptor-9 agonists, toll-like receptor-4 antagonists, and/or nuclear oligomerization domain-2 agonists for the treatment or prevention of toll-like receptor-4-associated disorders. US Patent No. 8188058. 29 May 2012.

117. Theofilopoulos AN, Baccala R, Beutler B, Kono DH. Type I interferons ( $\alpha / \beta)$ in immunity and autoimmunity. Annu Rev Immunol. 2005;23:307-335.

118. Utaisincharoen P, Kespichayawattana W, Anuntagool N, Chaisuriya P, Pichyangkul S, Krieg AM, et al. CpG ODN enhances uptake of bacteria by mouse macrophages. Clin Exp Immunol. 2003;132:70-75.

119. Ribes S, Ebert S, Regen T, Agarwal A, Tauber SC, Czesnik D, et al. Toll-like receptor stimulation enhances phagocytosis and intracellular killing of nonencapsulated and encapsulated Streptococcus pneumoniae by murine microglia. Infect Immun. 2010;78:865-871.

120. Fink MP. Animal models of sepsis. Virulence. 2014;5:143-153.

\section{Submit your next manuscript to BioMed Central and take full advantage of:}

- Convenient online submission

- Thorough peer review

- No space constraints or color figure charges

- Immediate publication on acceptance

- Inclusion in PubMed, CAS, Scopus and Google Scholar

- Research which is freely available for redistribution 